\title{
Relationship between microscopic analysis and quantitative and qualitative indicators of moisture susceptibility evaluation of warm- mix asphalt mixtures containing modifiers
}

\author{
Pooyan Farazmand, Parham Hayati \\ Department of Civil Engineering, Science and Research Branch, Islamic Azad University, Iran \\ Pooyanfarazmand1@gmail.com,P.hayati@srbiau.ac.ir
}

Hamid Shaker

Iran University of Science and Technology, Iran

h_shaker@civileng.iust.ac.ir, https://orcid.org/0000-0002-8524-1676

\author{
Sajad Rezaei \\ Department of Civil Engineering, Pooyesh Institute of Higher Education, Iran \\ rezaei@pooyesh.ac.ir, bttps:// orcid.org/0000-0001-7394-8001
}

\begin{abstract}
Given the defects of bitumen in asphalt mixtures particularly exposed to moisture, this study mainly aims to investigate the relationship between qualitative and quantitative results of moisture susceptibility tests on asphalt mixtures modified by ZycoTherm, nanoclay, nanosilica and SBS. The Marshall stability, modulus of resilience and indirect tensile strength tests are carried out. Boiling water and SEM qualitative tests are also used. Eventually, the qualitative tests results are digitalized through image processing by MATLAB and compared with the moisture susceptibility results of indirect tensile strength test.

For modulus of resilience testing, the results show that this modifier has the maximum impact on Marshall stability, improving it by about $23 \%$. For moisture susceptibility testing, the nanosilica-modified mixture has the maximum effect among anti-stripping additives, with an improvement by about $20 \%$. An investigation into the results of SEM images and boiling water test via MATLAB indicates the high accuracy of SEM images and their results show the most compatibility with the results of quantitative data.
\end{abstract}

KEYWORDS. Modifier; Moisture susceptibility; Image processing; Scanning electron microscopy (SEM) of bitumen.

\section{OPEN ACCESS}

Citation: Farazmand, P., Hayati, P., Shaker, H., Rezaei, S., N., Relationship between microscopic analysis and quantitative and qualitative indicators of moisture susceptibility evaluation of warm-mix asphalt mixtures containing modifiers, Frattura ed Integrità Strutturale, 51 (2020) 215-224.

Received: 14.09.2019

Accepted: 24.11.2019

Published: 01.01.2020

Copyright: (C) 2020 This is an open access article under the terms of the CC-BY 4.0, which permits unrestricted use, distribution, and reproduction in any medium, provided the original author and source are credited. 


\section{INTRODUCTION}

$\mathrm{T}$

he design and construction of asphalt pavements are essentially aimed to ensure the best performance under a variety of conditions, e.g. weather changes. Asphalt mixtures should possess proper durability and stability in order to achieve the best performance in asphalt pavements [1]. The efficiency of asphalt pavements mostly depends on the adhesion and bond between bitumen and aggregate. Stripping is a major failure of asphalt pavements due to the penetration of water between aggregate and bituminous binder, which occurs as a result of loss of adhesion between bituminous binder and aggregate [2]. Since moisture-induced damage in asphalt mixtures was first detected as a problem, considerable efforts have been made to specify its basic mechanisms and to develop a variety of tests for prediction and prevention of moisture damages [3].

The constituent characteristics play a key role in the properties of structural pavements. Although the bitumen content is far less than the aggregate in weight, it plays a significant role in the performance of asphalt pavements and the durability and stability of asphalt mixtures and any variation of performance of bitumen causes dramatic changes in the performance of asphalt mixtures [4]. The use of appropriate aggregate in asphalt mixtures usually can prevent stripping, but the bitumen modification is also of great importance. The application of modified bitumen can reduce stripping. In addition to impacts on the bond between aggregate and bitumen, anti-stripping materials can change the hardness and rutting resistance and increase or decrease the propagation of cracks[5].

On the other hand, the image processing of asphalt mixture specimens was first conducted for a project entitled "thermography image processing in an asphalt core" in 1993 at the University of Southern California. This study was carried out in cooperation with civil, electrical engineering, radiology, metallurgy, chemical engineering and asphalt experts. The study aimed to investigate the asphalt core after construction and to find deformations and failures before and after loading. This technique became popular in pavement engineering after this study [6]. Later, a variety of image processing methods were employed for 3D modeling of these specimens [7] [8].

In 2013, Ki Hoon conducted an analysis of structure of asphalt mixtures using digital image processing techniques [9], which was developed according to the research by ZELELEW et al [10]. Different components of asphalt mixture and volumetric information were assessed in this study. The applied methods were based on the detection of threshold between the air, mastic (bitumen and filler) and aggregate according to the experimental data.

This study aims to evaluate the relationship between quantitative and qualitative results of moisture susceptibility tests on asphalt mixtures containing ZycoTherm, nanoclay, SBS and nanosilica modifiers. It is investigated using indirect tensile strength, Marshall stability, modulus of resilience, boiling water and SEM tests.

\section{MATERIALS}

$\mathrm{I}$

n this study, bitumen performance grade PG 58-22 is used, produced by the Pasargad Oil Company in Tehran according to the standard (Tab. 1). Calcareous aggregate extracted from the Telo mine in Tehran is also used, graded as shown in Fig. 1. The grading is according to the Iranian Highway Asphalt Paving Code No. 234 (grading No. 4).

\begin{tabular}{llllc}
\hline \multicolumn{1}{c}{ Properties } & Testing method & \multicolumn{2}{c}{ Standard limits } & Bitumen 60-70 \\
& & Lower limit & Upper limit & \\
Specific weight at $25{ }^{\circ} \mathrm{C}$ & ASTM D-70 & 1.01 & 1.06 & 1.03 \\
Penetration grade at $25{ }^{\circ} \mathrm{C}$ & ASTM D-5 & 60 & 70 & 64 \\
Softening point $\left({ }^{\circ} \mathrm{C}\right)$ & ASTM D-36 & 49 & 56 & 54 \\
Ductility at $25{ }^{\circ} \mathrm{C}$ & ASTM D-113 & 100 & & 102 \\
Fire point & ASTM D-92 & 250 & 305 \\
\hline
\end{tabular}

Table 1: Specifications of bitumen

In this study, nano-Zycotherm, nanoclay, nanosilica, SBS modifiers are used at their optimum contents. The modifiers are mixed with bitumen using a high shear mixer at $4200 \mathrm{rpm}$ for $45 \mathrm{~min}$ at mixing temperature of $175^{\circ} \mathrm{C}$. Eventually, the specimens are named in Tab. 3 .

Optimum bitumen content is determined 5.1 for the control specimen using the Marshall method, according to which all specimens are made and evaluated. 


\begin{tabular}{|c|c|c|c|c|}
\hline \multirow[t]{2}{*}{ Description } & \multirow[t]{2}{*}{ Test standard } & \multicolumn{2}{|c|}{$\begin{array}{l}\text { Allowable limits of the } \\
\text { Code No. } 234\end{array}$} & \multirow[t]{2}{*}{$\begin{array}{l}\text { Test } \\
\text { results }\end{array}$} \\
\hline & & Binder & Top coat & \\
\hline Maximum abrasion by Los Angeles abrasion test ( $\%)$ & $\begin{array}{l}\text { AASHTO } \\
\text { T96 }\end{array}$ & 40 & 30 & 22.3 \\
\hline Maximum flakiness index $(\%)$ & BS 812 & 30 & 25 & 16 \\
\hline $\begin{array}{l}\text { Minimum percent of particles with two fractured } \\
\text { faces for sieve No. } 4(\%)\end{array}$ & ASTM D5821 & 80 & 90 & 93 \\
\hline $\begin{array}{l}\text { Maximum percent of water absorption (coarse- } \\
\text { grained aggregate) }\end{array}$ & $\begin{array}{l}\text { AASHTO } \\
\text { T85 }\end{array}$ & 2.5 & 2.5 & 2.2 \\
\hline $\begin{array}{l}\text { Maximum percent of water absorption (fine-grained } \\
\text { aggregate) }\end{array}$ & $\begin{array}{l}\text { AASHTO } \\
\text { T84 }\end{array}$ & 2.8 & 2.5 & 2.4 \\
\hline True specific gravity of coarse-grained aggregate & ASTM C127 & - & - & 2.59 \\
\hline True specific gravity of fine-grained aggregate & ASTM C128 & - & - & 2.32 \\
\hline
\end{tabular}

Table 2: Specifications of aggregate

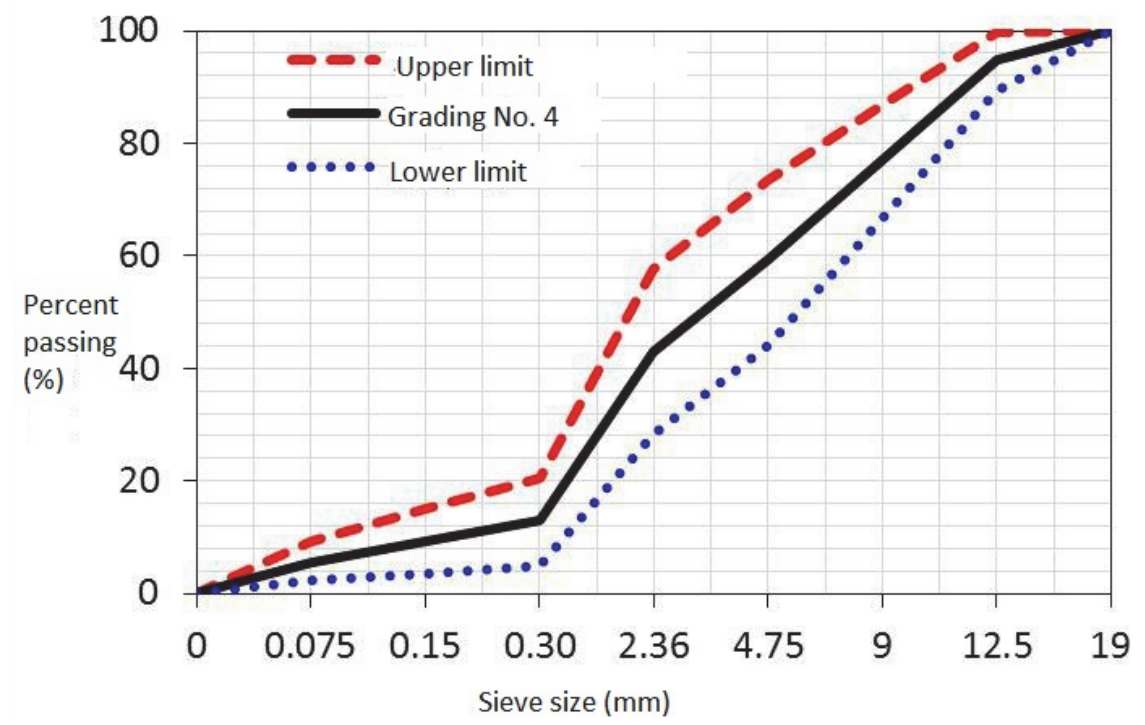

Figure 1: Particle size distribution for stone mastic asphalt mixture.

\begin{tabular}{lllll}
\hline No & \multicolumn{1}{c}{ Mix design } & \multicolumn{1}{c}{ Modifier } & \multicolumn{2}{c}{$\begin{array}{c}\text { Abbrev. } \\
\text { name }\end{array}$} \\
& & \multicolumn{3}{c}{ Applied content } \\
1 & Control & AC & 0 \\
2 & Modified by ZycoTherm & ZycoTherm & $\mathrm{Za}$ & $0.1 \%$ of bitumen in weight [11] \\
3 & Modified by nanoclay & Nanoclay & $\mathrm{Nc}$ & $4 \%$ of bitumen in weight [12] \\
4 & Modified by SBS & SBS & SB & $4.5 \%$ of bitumen in weight [13] \\
5 & Modified by nanosilica & Nanosilica & NS & $4 \%$ of bitumen in weight [14] \\
\hline
\end{tabular}

Table 3: Name of specimens and percent of each material for optimum bitumen content.

\section{EXPERIMENTAL TEST}

Initial tests

T $\mathrm{n}$ this study, the Marshall stability test is done according to the ASTM D-1559, the modulus of resilience test is done according to the ASTM D-4123, the moisture susceptibility of mixture is measured based on indirect tensile strength test according to the AASHTO T283 and the boiling water test is done according to the ASTM D-3625 [15] [16] [17]. 


\section{SEM}

Scanning electron microscopy (SEM) is a qualitative investigation which can be used to analyze various properties of a mixture by processing of captured images. To capture images, the specimens are taken from the first quartile $(250 \mathrm{~g})$ of mixture and put in boiling water for $10 \mathrm{~min}$. Then, about $1.18 \mathrm{~g}$ of the specimen is taken and placed in the machine and the images are prepared.

\section{Image processing technique and comparison of results}

Using MATLAB as a practical software has been seen in previous recent research [18]. In this research, MATLAB programing as a neural network has been employed and the properties of asphalt were estimated with using this software. In the present study, The MATLAB software is utilized to quantify the qualitative results of image processing. In this process, the pixels of each image are converted to 0 and 1 . Accordingly, a value is determined as histogram threshold on the grayscale by converting the image to a negative (black and white) image and assigning a set of values to each greyscale shade. In this study, the threshold is considered 128 with black shade corresponded to 0 and white shade corresponded to 255 and the pixels of black and white shades are specified. Hence images taken from boiling water and SEM test specimens are imported into MATLAB and the outputs, i.e. white and black percent, as quantitative results are compared to the results of Marshall Stability, modulus of resilience and moisture susceptibility of mixture based on indirect tensile strength test. The Kruskal-Wallis test is thus applied for the comparison. This is a non-parametric statistical test. Non-parametric tests have particular conditions corresponding to the parametric F-test; they are applied like the real F-test when the number of population groups is independent and more than 2 to $\mathrm{K}$ groups are available. The measurement scale for Kruskal-Wallis test should be at least ordinal.

\section{RESULT}

\section{Marshall Stability}

7 he results of Marshall stability test on modified and non-modified specimens are illustrated in Fig. 2. As the chart shows, all additives have a positive effect on Marshall stability and this positive effect varies for different specimens. The additives increase the hardness in SBS, nanoclay and nanosilica modified specimens, causing an increased Marshall stability. The increase for ZycoTherm modified specimens is less than the other.

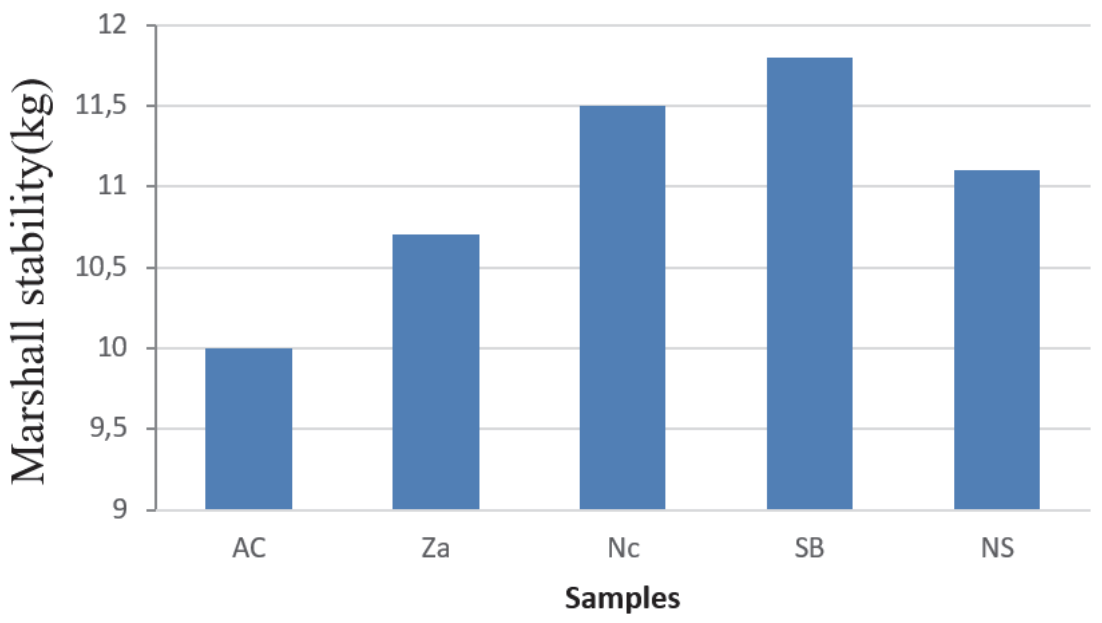

Figure 2: Results of Marshall stability for modified and non-modified specimens

\section{Modulus of resilience}

The results of this test are demonstrated in Fig. 3. The modulus of resilience is tested for the assessment of hardening in the mixture and gives the designer an important parameter for determining the thickness. In this study, all additives except ZycoTherm increase the modulus of resilience. However, the nanoclay, SBS and nanosilica modified mixtures experience higher increases. To justify the trend, it can be deduced that the hardness somewhat increases for mixtures containing nanoclay and SBS. On the other hand, the decrease for the specimen containing ZycoTherm can be justified in regard to the additive properties; so that SBS and nanoclay increase the hardening in the bitumen and, consequently, the asphalt and ZycoTherm reacts vice versa. 


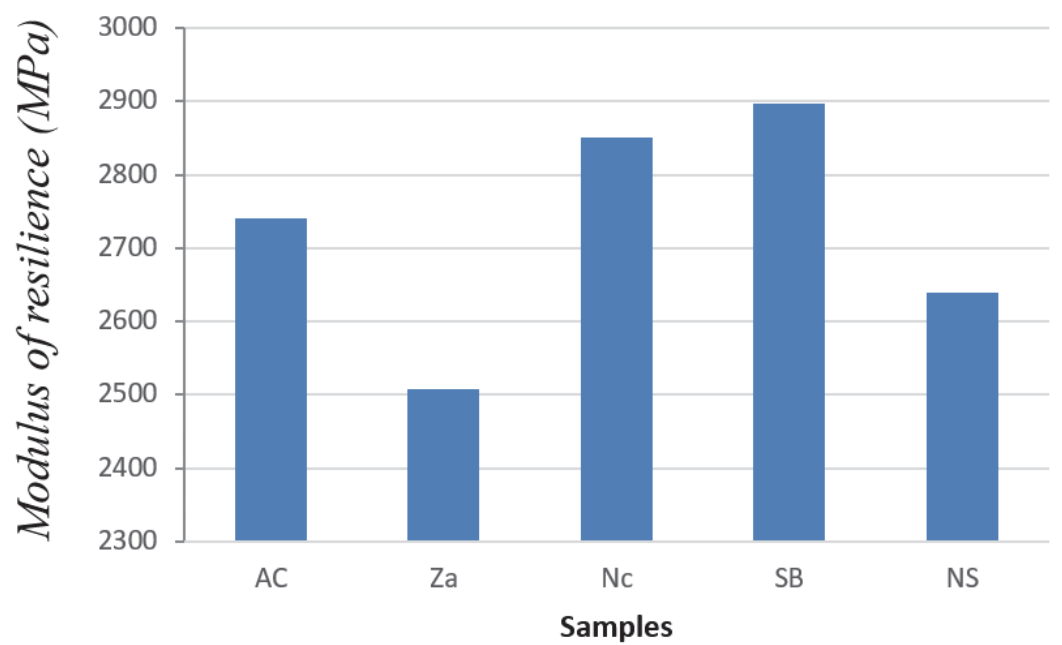

Figure 3: Results of modulus of resilience for modified and non-modified specimens

\section{Indirect tensile strength}

Fig. 4 shows the results of indirect tensile strength test for both dry and wet conditions. As demonstrated in the chart, the addition of modifiers results in significant changes in the specimens and alters both wet and dry strengths and the variations are almost the same under wet and dry conditions for each specimen. For the ZycoTherm-modified specimen, its wet strength is almost equal to that of the control specimen, but its dry strength declines and approaches its wet strength. For example, the wet and dry strengths of nanoclay, nanosilica and SBS modified specimens increase in comparison with the control specimen, along which the difference between wet and dry strengths decreases.

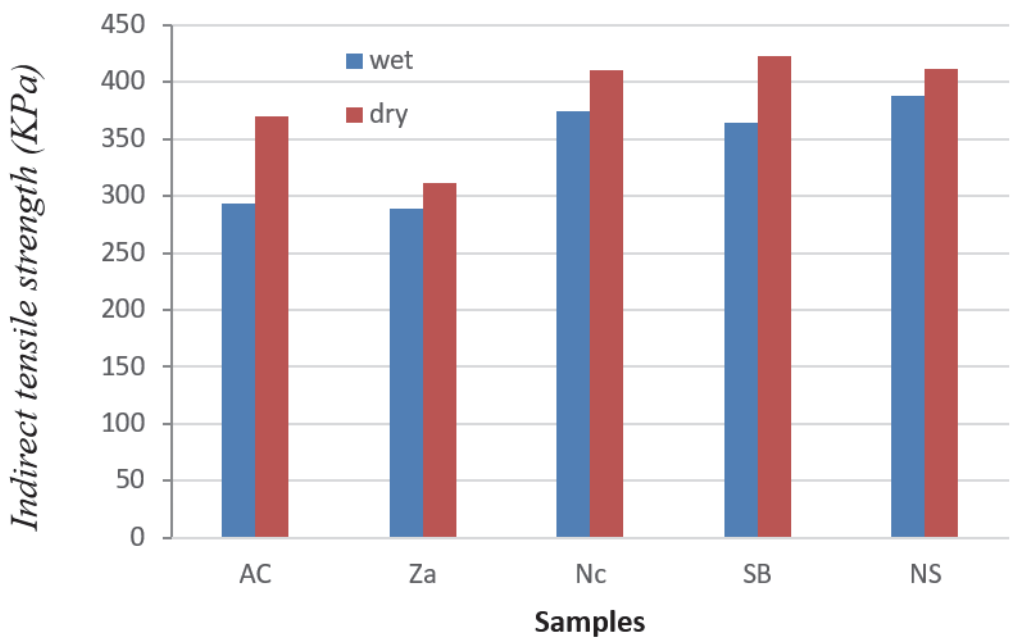

Figure 4: Results of indirect tensile strength for modified and non-modified specimens.

\section{Moisture susceptibility based on indirect tensile strength (ITS)}

The moisture susceptibility is described in terms of the parameter TSR which is calculated through dividing the wet strength by dry strength in indirect tensile strength test and expressed in percent. In the figure above, this parameter is presented for the control and modified specimens in form of a chart. As shown in the chart, all additives improve the stripping and enhance the TSR. This increase is higher for the specimens containing ZycoTherm and nanosilica than the other. To justify the trend, it can be argued that as the wet and dry strengths approach together, the moisture susceptibility improves. Depending on properties of the material, however, this approach is either accompanied by a decrease in dry tensile strength or an increase in wet tensile strength. For the ZycoTherm-modified specimen, for example, the improvement of moisture susceptibility leads to a decrease in dry indirect tensile strength, while other specimens undergo a rise in both strengths with the wet strength increased more than the dry strength. 


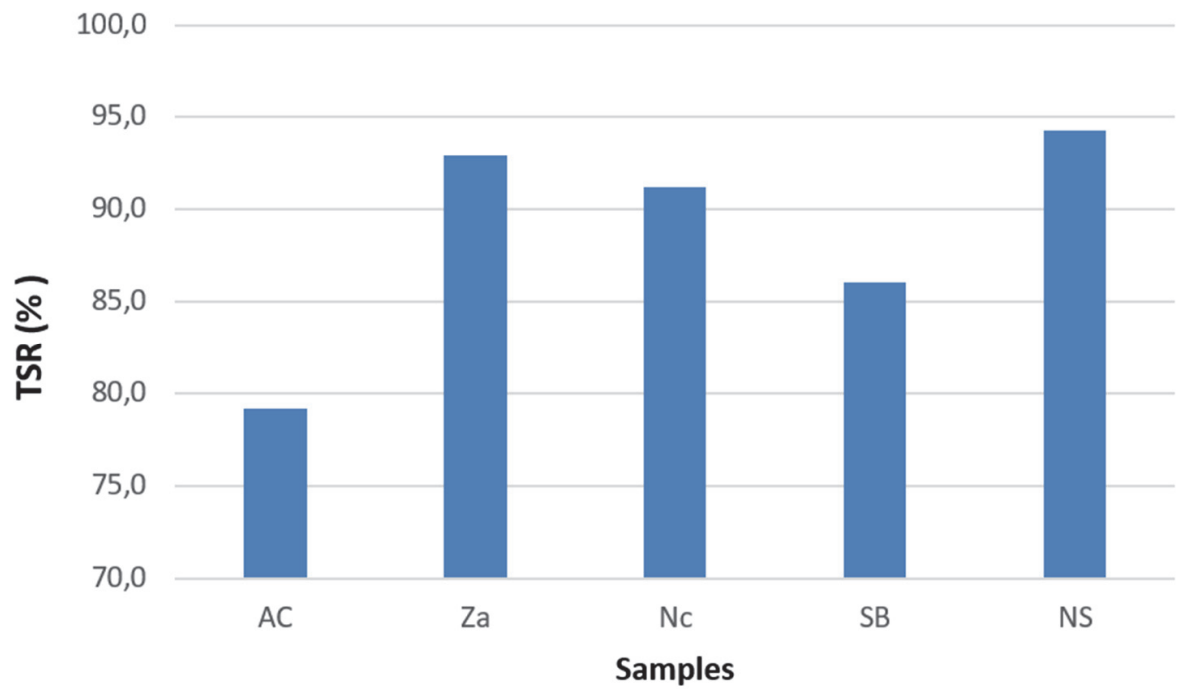

Figure 5: Quantitative results of moisture susceptibility for modified and non-modified specimens.

\section{Boiling water}

The qualitative experiments include both boiling water and SEM tests, so that the results of boiling water test are assessed initially.

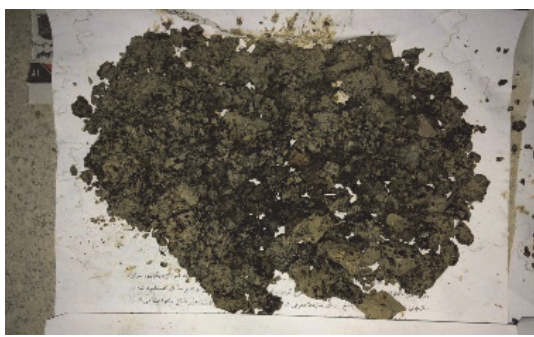

Control specimen (AC)

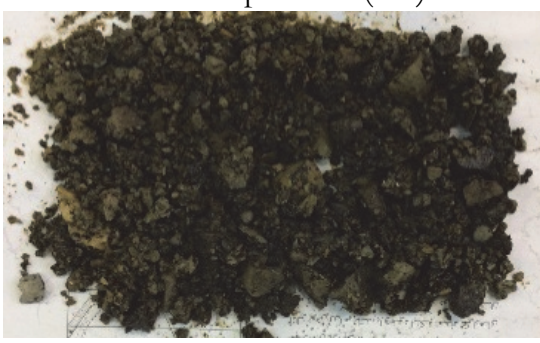

SBS-modified specimen (SB)

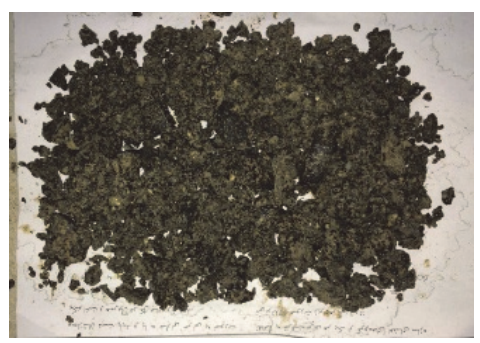

Zycotherm-modified specimen (Za)

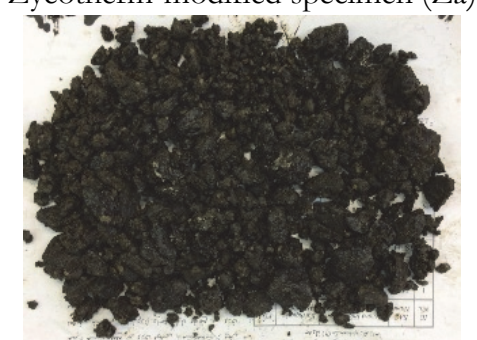

Nanosilica-modified specimen (NS)

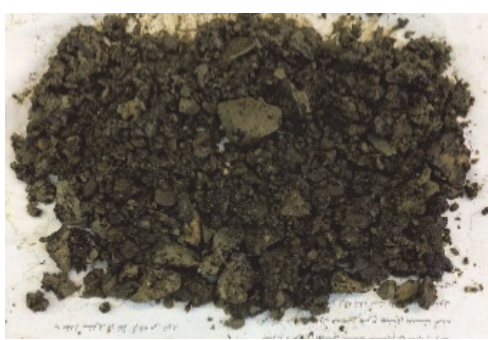

Nanoclay-modified specimen (NC)

Figure 6: Results of boiling water for modified and non-modified specimens

The results of boiling water test are represented in Fig. 6. As explained previously, the results of boiling water test indicate the qualitative result of moisture susceptibility. As shown in the figures, the control specimen experiences the highest stripping, while the specimen containing nanosilica undergoes the lowest stripping.

\section{SEM}

The results of SEM are represented in Fig. 7. Two types of SEM images can be presented: the first image is related to the qualitative analysis of stripping, in which the white points indicate higher bitumen content and the black points show the lower bitumen content; the second image represents the distribution of nanomaterials within the mixture, which is presented for modifiers containing nanomaterials. 


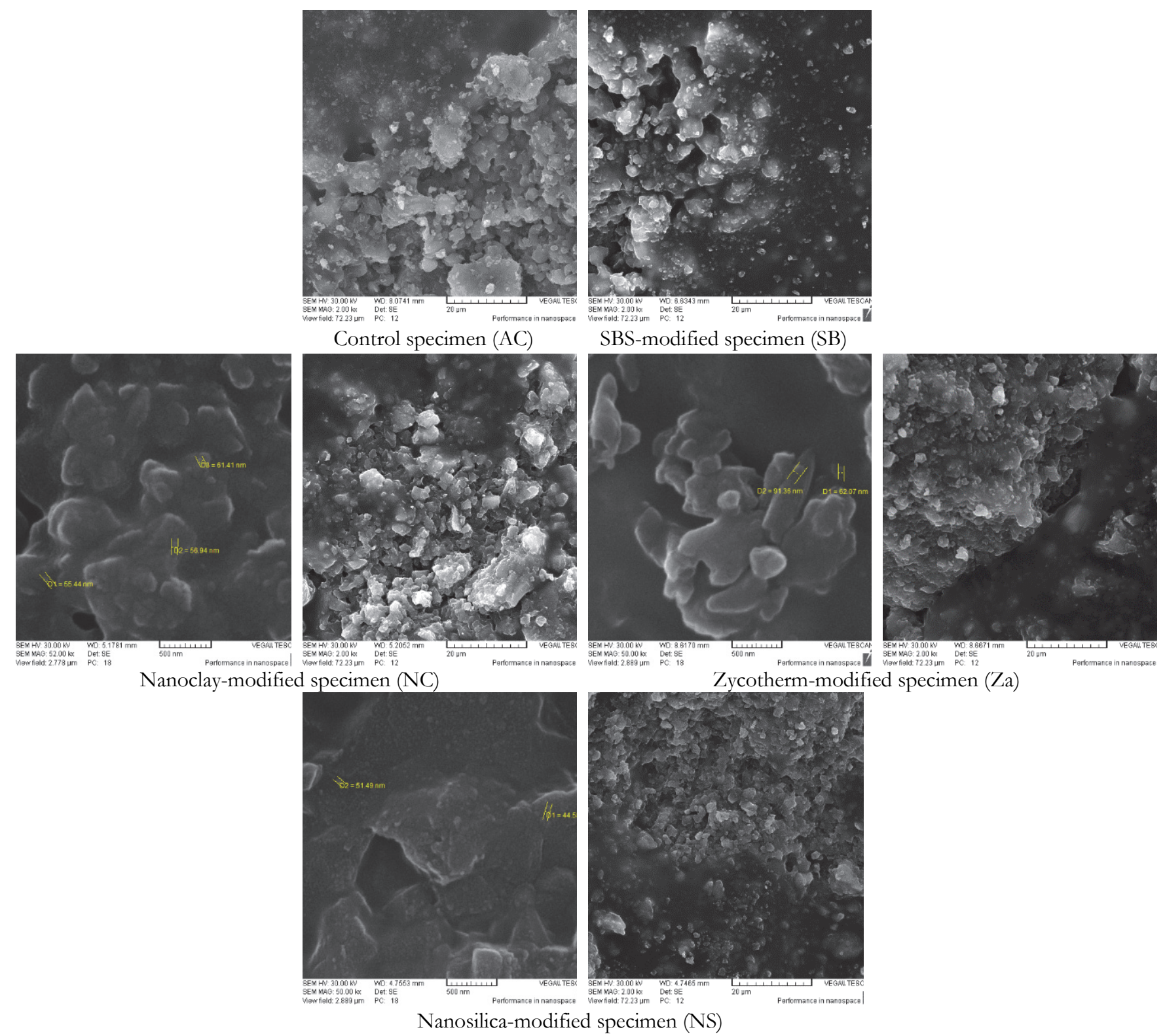

Figure 7: Results of SEM test for modified and non-modified specimens (Samples containing nanoparticles have also been taken for further zooming).

\section{COMPARISON OF QUANTITATIVE AND QUALITATIVE RESULTS}

7 he images shown in Figs. 6 and 7 are imported to the MATLAB software and the outputs are given in Tabs. 4 and 5.

\begin{tabular}{cccc}
\hline Specimen & Stripped percent $(\mathrm{A})$ & Non-stripped percent $(\mathrm{B})$ & $\mathrm{C}=(\mathrm{A} / \mathrm{B}) * 100$ \\
$\mathrm{AC}$ & 19.26 & 80.74 & 24 \\
$\mathrm{Za}$ & 6.55 & 93.45 & 7 \\
$\mathrm{Nc}$ & 5.34 & 94.66 & 6 \\
$\mathrm{SB}$ & 0.61 & 99.39 & 1 \\
$\mathrm{NS}$ & 1.16 & 98.84 & 1 \\
\hline
\end{tabular}

Table 4: MATLAB output for boiling water specimens 


\begin{tabular}{cccc}
\hline Specimen & Stripped percent $(\mathrm{A})$ & Non-stripped percent $(\mathrm{B})$ & $\mathrm{C}=(\mathrm{A} / \mathrm{B})^{*} 100$ \\
$\mathrm{AC}$ & 22.97 & 77.03 & 30 \\
$\mathrm{Za}$ & 3.12 & 96.88 & 3 \\
$\mathrm{Nc}$ & 0.8 & 99.2 & 1 \\
$\mathrm{SB}$ & 13.78 & 86.22 & 16 \\
$\mathrm{NS}$ & 1.09 & 98.91 & 1 \\
\hline
\end{tabular}

Table 5: MATLAB output for SEM specimens

The comparison of results of parameter $\mathrm{C}$ with those of (100-TSR) can indicate the relationship between quantitative and qualitative results of moisture susceptibility.

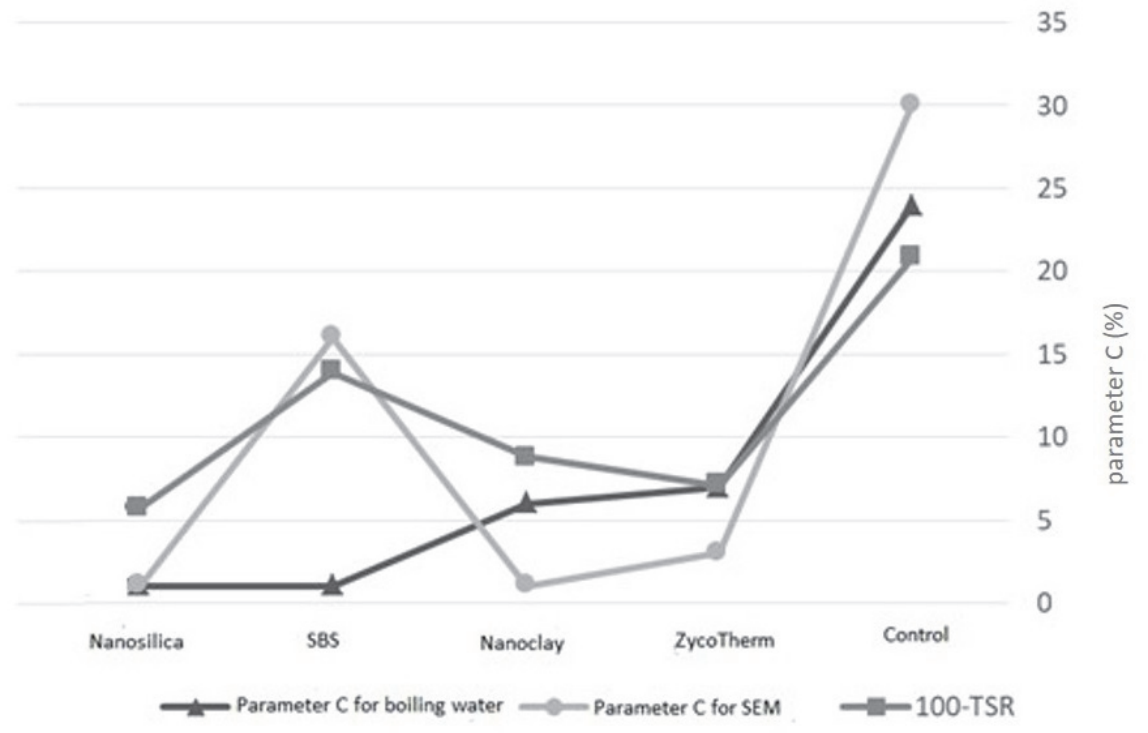

Figure 8: Investigation into results of parameter C for boiling water and SEM tests and results of (100-TSR)

According to Fig. 8, the more stripping occurs in the specimen, the higher result of parameter $\mathrm{C}$ is obtained for the specimen; and the less stripping happens in the specimen, the lower result of parameter $\mathrm{C}$ is obtained and its value approaches 1 or 0. Another important point is related to the SBS-modified specimens. The evaluation of parameter C suggests that the results of boiling water test for the SBS-modified specimen are less accurate compared to the results of SEM test for the same specimen and For other samples, however, the situation was reversed, i.e. the boiling water test returned closer results, implying that there is no general principle in this respect. Considering the higher accuracy of the SEM analysis and the captured images in this analysis, it could be stipulated that the only advantage offered by the SEM analysis, as compared to the boiling water test, was the acquisition of more accurate images, which could somehow reduce the resultant error

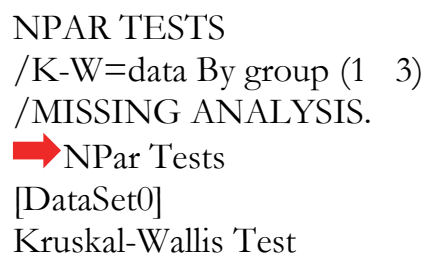

\begin{tabular}{cccc}
\multicolumn{4}{c}{ Ranks } \\
\hline \multicolumn{3}{c}{ data } & \multicolumn{3}{c}{ Group } & N & Mean rank \\
& 1 & 7 & 9.79 \\
& 2 & 7 & 8.79 \\
& 3 & 7 & 14.43 \\
& Total & 21 & \\
\hline
\end{tabular}

\section{Table 6: Results of statistical test}

Considering the obtained value of sig (0.185, as tabulated in Tab. 6), the Kruskal-Wallis instability test method (the value of sig was not smaller than 0.05) indicated that the difference between results of the boiling water test and SEM analysis was no significant. 


\section{CONCLUSION}

$\mathrm{T}$

his study is associated with an investigation into the relationship between quantitative and qualitative results of moisture susceptibility tests on asphalt mixtures modified by ZycoTherm, nanoclay, nanosilica and SBS the following results are obtained:

- The results of Marshall stability test indicate that all additives lead to better results compared to the control specimen. Hence it can be concluded that all additives used in this study improve the compressive strength.

- The results of modulus of resilience test suggest that nanosilica and ZycoTherm reduce the modulus of resilience, while other additives such as Nano silica and SBS improve the modulus of resilience in comparison with the control specimen.

- According to the results of indirect tensile strength test, the indirect tensile strength is improved almost in all wet specimens. For dry specimens, all additives except ZycoTherm improve the dry indirect tensile strength with the best result obtained for the SBS samples.

- The results of moisture susceptibility test based on indirect tensile strength (ITS) show that stripping is improved in all specimens. Moreover, it is possible to observe the improvement process of stripping through the assessment of wet/dry indirect tensile strength ratio (TSR). For example, ZycoTherm creates the trend by reducing the wet indirect tensile strength, while stripping is improved in other specimens by increasing both wet and dry tensile strengths with the wet condition improved more than the dry condition.

- Given the results of qualitative tests, it can be concluded that these tests supplement and confirm quantitative tests. Moreover, it is possible to analyze the images by assessing the results of these tests, e.g. SEM test, along with those of quantitative tests and present a single process for the images.

- The results of investigation into the relationship between boiling water and SEM tests and moisture susceptibility quantitative tests demonstrate that, in fact, qualitative tests have a relatively high accuracy.

\section{REFERENCES}

[1] Xiao, F., et al. (2010). Influence of antistripping additives on moisture susceptibility of warm mix asphalt mixtures. Journal of Materials in Civil Engineering 22.10, pp. 1047-1055.

[2] Behiry, A. E., Abu El-Maaty. Laboratory evaluation of resistance to moisture damage in asphalt mixtures. Ain Shams Engineering Journal 4.3 (2013): 351-363.

[3] Behbahani, H., et al. Evaluation of performance and moisture sensitivity of glasphalt mixtures modified with nanotechnology zycosoil as an anti-stripping additive. Construction and Building Materials 78 (2015): 60-68

[4] Jahanian, H. R., Shafabakhsh, Gh. and Divandari, H. (2017). Performance evaluation of Hot Mix Asphalt (HMA) containing bitumen modified with Gilsonite. Construction and Building Materials 131, pp.156-164.

[5] Yilmaz, M., and Yalcin, E. (2016). The effects of using different bitumen modifiers and hydrated lime together on the properties of hot mix asphalts. Road Materials and Pavement Design 17.2, pp. 499-511.

[6] Wang, H., Hao, P. (2010). Numerical simulation of indirect tensile test based on the microstructure of asphalt mixture. Journal of Materials in Civil Engineering, 23.1, pp. 21-29.

[7] Moon, K. H., Falchetto, A., Jeong, J. H. (2013). Microstructural analysis of asphalt mixtures using digital image processing techniques. Canadian Journal of Civil Engineering, 41.1, pp. 74-86.

[8] Zelelew, H. M., Papagiannakis, A. T. and Masad, E. (2008). Application of digital image processing techniques for asphalt concrete mixture images. In: The 12th International Conference of International Association for Computer Methods and Advances in Geomechanics (IACMAG). pp. 119-124.

[9] Nejad, F. M., et al. (2015). An Image Processing Approach to Asphalt Concrete Feature Extraction. Journal of Industrial and Intelligent Information, 3.1.

[10] Al-Qadi, I. L., et al. (2010). In-place hot-mix asphalt density estimation using ground-penetrating radar. Transportation research record, 2152.1, pp. 19-27.

[11] Ayazi, M. J., Moniri, A. and Barghabany, P. (2017). Moisture susceptibility of warm mixed-reclaimed asphalt pavement containing Sasobit and Zycotherm additives. Petroleum Science and Technology 35.9, pp. 890-895.

[12] Galooyak, S., Sadeghpour, B., Dabir, A., Nazarbeygi, E., Moeini, A. and Berahman, B. (2011). The effect of nanoclay on rheological properties and storage stability of SBS-modified bitumen. Petroleum Science and Technology 29(8) pp. 
850-859.

[13] Rezaei, S., Ziari, H. and Nowbakht, S. (2016). Low temperature functional analysis of bitumen modified with composite of nano-SiO2 and styrene butadiene styrene polymer. Petroleum Science and Technology 34(5), pp. 415-421.

[14] Rezaei, S., Khordehbinan, M., Fakhrefatemi, S. M. R., Ghanbari, S., and Ghanbari, M. (2017). The effect of nano-SiO $\mathrm{S}_{2}$ and the styrene butadiene styrene polymer on the high-temperature performance of hot mix asphalt. Petroleum Science and Technology, 35(6), pp. 553-560.

[15] American Association of State Highways and Transportation Officials. Resistance of compacted bituminous mixture to moisture induced damage AASHTO D4123.

[16] American Association of State Highways and Transportation Officials. Resistance of compacted bituminous mixture to moisture induced damage AASHTO T283.

[17] American Association of State Highways and Transportation Officials. Resistance of compacted bituminous mixture to moisture induced damage AASHTO D3625.

[18] Ameri, M., Nemati, M., Shaker, H. and Jafari, F. (2019) Experimental and numerical investigation of the properties of the Hot Mix Asphalt Concrete with basalt and glass fiber, Frattura ed Integrità Strutturale, 13(50), pp. 149-162.

DOI: $10.3221 /$ IGF-ESIS.50.14. 